\title{
Correction to: Development and Evaluation of a Machine Learning Prediction Model for Flap Failure in Microvascular Breast Reconstruction
}

\author{
Anne C. O’Neill, MBBCh, PhD' ${ }^{1}$, Dongyang Yang, PhD ${ }^{2}$, Melissa Roy, MD, MSc ${ }^{1}$, \\ Stephanie Sebastiampillai, BSc ${ }^{1}$, Stefan O. P. Hofer, MD, $\mathrm{PhD}^{1}$, and Wei $\mathrm{Xu}_{\mathrm{MhD}} \mathrm{Ph}^{2}$ \\ ${ }^{1}$ Division of Plastic Surgery, Department of Surgery and Surgical Oncology, University Health Network, University of \\ Toronto, Toronto, Canada; ${ }^{2}$ Department of Biostatistics, Princess Margaret Cancer Centre, University Health Network, \\ Toronto, Canada
}

CORRECTION TO: ANN SURG ONCOL (2020) 27:3466-3475 HTTPS://DOI.ORG/10.1245/S10434-020-08307-X

In the original online version of this article, Dongyang Yang's given name was misspelled. The original article was corrected.
Publisher's Note Springer Nature remains neutral with regard to jurisdictional claims in published maps and institutional affiliations.

The original article can be found online at https://doi.org/10.1245/ s10434-020-08307-x.

(C) Society of Surgical Oncology 2021

Published Online: 1 November 2021

A. C. O'Neill, MBBCh, PhD

e-mail: Anne.O’Neill@uhn.ca 